\title{
A Systematic Review on the Flipped Classroom Model as a Promoter of Curriculum Innovation
}

\section{José Alberto Lencastre}

Research Centre on Education (CIEd), Institute of Education, University of Minho, Portugal, jlencastre@ie.uminho.pt

\section{José Carlos Morgado}

Research Centre on Education (CIEd), Institute of Education, University of Minho, Portugal,jmorgado@ie.uminho.pt

\section{Thiago Freires}

Research Centre on Education (CIEd), Institute of Education, University of Minho, Portugal,freiresle@gmail.com

\section{Marco Bento}

Research Centre on Education (CIEd), Institute of Education, University of Minho, Portugal, macbento@hotmail.com

Assuming the evident relationship between innovation and technology, and the corresponding impact in the educational field, this article contemplates a systematic review on the resource on flipped classroom model in non-tertiary education. 181 studies were reviewed with the purpose of establishing and apprehending the connections between the flipped learning and its potential to promote curriculum innovation. Data analysis allowed the building of a three-level model in which the relations of the flipped classroom model and curriculum are organized in terms of (i) outcomes support, (ii) institutional change and (iii) classroom instruction modus operandi. Results suggest substantial potential of the flipped model to flip the curriculum and even the school culture. To meet such end, innovation must be perceived as an institutional strategy, making sure all stakeholders hold a part in the adaptative process of fostering change. Moreover, there is evidence that the model can ease the articulation and consolidation of constructivist approaches in schooling, a perspective that enhances the movement for student-centred logics in education. The review novelty lies on its building of a model that can work as a guide for reflecting on the approach and for underpinning future action.

Keywords: flipped classroom, curriculum, innovation, schooling, systematic review 


\section{INTRODUCTION}

Contemporary world is characterized by an intense influx of information in societies that are fluid, aimed at immediacy, guided by ongoing transformation and reigned by unpredictability and uncertainty in terms of future. In this era for which change is a remarkable vector, innovation stands out, necessarily being pushed into education as well. For schools, this scenario means growing pressure and greater social expectations concerning the institution's role, within its mission towards the preparation of youth to face the labour market and integrate the civil society (Willness \& Bruni-Bossio, 2017). In a world of intense change and deep social transformation, the discussion of education should be of utmost interest, privileging what it means in the present and for the future, acknowledging that despite external influences that might difficult its domain, it continues to secure its importance as an essential nutrient of human development and social sustainable cohesion (Morgado, 2017).

In education, the innovation rise is permeated by a key feature of the contemporary global world - technology. The digital crescendo permeates all spheres of society and in schooling context provides opportunities to foster new learning cultures (Thomas \& Brown, 2011). Because school has to address what is understood as the $21^{\text {st }}$ century competences and needs (OECD, 2010; Lafarrière, Law \& Montané, 2012), it is of primary relevance that it assesses what is available as resources and what is relevant as means to correspond to the goals socially established. According to OECD (2010), the increasing technological richness of the world promotes new concerns in the educational domain, at the same time it generates expectations that schools take the lead of knowledge societies. Leahy, Holland \& Ward (2019) apprehend this call for transformation in the educational field under the label of a Fourth Industrial Revolution, which is characterized by the convergence of physical, digital, and biological technologies that apparently change how or what people do and what it means to be human. In short, there is acknowledgment that upbringing is changing, partly, due to the saturation of technology and information in global social scales, meaning that several challenges are then imposed to the educational field (Baruch and Erstad, 2018).

Assuming the evident relationship established between innovation and technology, there is argument that school institutional reorganization and learning orientation cannot ignore another relevant tie, the one between technology and pedagogy (Earle, 2002). Only upon a process of wholeness in which resources and methods are integrated, one can further advance successful outcomes in education. The integration of technology in schools, as widely reported on the literature implies that new methods demand deployment of collaborative cultures, advancement of pedagogical and technical training for teachers, besides institutional technical support if a sustainable innovative mandate is desired (Snoeyink \& Ertmer, 2001; Bingimlas, 2009; Laferrière, Law \& Montané, 2012; Chandra \& Mills, 2015; Lakkala, 2015; Greany \& Waterhouse, 2016; Louws et al., 2017).

Aiming at enhancing students' outcomes and resourcing on technology, the method known as flipped classroom has gained vivid attention (Cargile \& Sheats, 2015; Lai \& Hwang, 2016). According to Durak (2018), very different approaches are available on 
how integrating technology in education to increase success, being the flipped classroom (FC) a prominent model. Despite varying features found in the literature, FC is recognized mainly for its blended learning nature and the shift of tasks traditionally executed in classrooms to external environments (e. g. Kong, 2014; 2015; Hendry et al., 2017; Moran, 2018; Villalba, Castilla \& Redondo-Duarte, 2018).

For Villalba, Castilla \& Redondo-Duarte (2018), the concept of assigning a task to do before class is not exactly something new. The difference is that now there is systematic use of technology to deliver declarative knowledge. As an advantage, teachers can mobilize class time to more student-centred activities as it is the case for discussion, teamwork, projects and other active learning approaches (Durak, 2018; Hendry et al., 2017; Cargile \& Sheats, 2015) in which knowledge construction presupposes extensive and meaningful interaction with peers and teachers (Kong, 2014; 2015).

The flipped classroom out of class time is also regarded as an important element for personal development, considering that it promotes learning with respect to different individual paces, times, capabilities and necessities (Durak, 2018; Kong, 2014; 2015; Lai \& Hwang, 2016). Associated to this idea, literature has documented evidence that FC model increases achievement in various branches (Ayçiçek \& Yelken, 2018). As Hendry et al. (2017) highlight, the approach has a strong constructivist theoretical basis leading to the acknowledgment that each learning partner can have their own understanding of knowledge (Liu \& Feng, 2015).

Despite the advantages provided by the flipped classroom in terms of flexibility and individualization of the learning process (Durak, 2018), while there is recognition that the FC model can enhance classroom engagement (Ayçiçek \& Yelken, 2018), some research has also drawn attention to the idea that not all students might adapt easily to its procedures, either because they do not feel motivated by school instruction in general or due to attitudes towards academic innovation (Moran, 2018). Consistent with this concern, some strategies have been placed in order to foster achievements through the FC model. Durak (2018), for example, invests in the concept of readiness, arguing that flipped classroom readiness and related indicators are predictors of engagement to course tasks. Likewise, the author affirms that competence of the preservice and inservice teachers is crucial as students' since they are the practitioners of the FC concept. Lai \& Hwang (2016) consider self-regulation strategy essential for improving students' self-efficacy in environments mediated by the FC. These authors defend the importance of teachers' guidance as well and suggest that without proper assistance, students might show low self-regulated behaviours and little responsibility along the learning process.

It is noteworthy that, mainly, research available on the flipped method corroborates a scenario of students' excitement with the model (Kong, 2015) and successful achievements (Lai \& Hwang, 2016; Kostaris et al., 2017; Ayçiçek \& Yelken, 2018), which of course can be associated with a set of other features such as technology infrastructure, teacher training and learning environment development (Hendry et al., 2017; Villalba, Castilla \& Redondo-Duarte, 2018). It is then considering this innovative character of the flipped classroom method and the potential it encompasses to endorse curricular change that we address the theme, aiming at organizing the knowledge 
provided so far as a means to further exploit innovation in educational setting, specifically, in the primary and secondary level. Next sections present the context in which this study was developed, cover the methodology applied and present architecturally analytical data.

\section{BACKGROUND}

Our interest in innovative approaches in education and curricular flipping is directly related to the ongoing project Digital migration and curricular innovation: giving new meaning to experience and rekindling teacher profession after 50 (Rekindle +50$)$, which is assembled by two educational sciences faculties in Portugal in association with two teachers' training centres from central and northern areas of the country. It focuses on teachers over 50 years old and on renewing their commitment to teaching and curricular innovation through the deployment of mobile technologies in educational context.

Understanding that Portuguese teacher force has undergone accelerated process of ageing (OCDE, 2018), facing situations of instability and demotivation, therefore, professional disenchantment, and observing the growing technological enrichment of contemporary societies, the project was designed as an attempt to address teachers' dissatisfaction through empowering their long-term trajectories with digital knowledge. In broad terms, the action was designed to bridge the gap between veteran teachers (Carrilo \& Flores, 2018; Orlando, 2014) interests and the digital culture, arranging room for interconnectivity around teachers and students' alterities, usually set apart, strengthening a common ground through technology language.

Operationally, the project links research to intervention and to basic and secondary school teachers' training. Rekindle +50 workplan involves diagnosing, monitoring and evaluating the change in practices, within a movement on digital migrations, with focus on the possible sustainability of this move in the short and medium term. Along 2019, around 40 teachers of different subject domains from pre-school, primary and secondary education participated in educational actions under the project reference. In these actions, teachers were exposed to diverse pedagogical methodologies in dialogue with technology. It is within this framework that researchers and teacher educators of the project have got interested in a deep understanding of the flipped method as a tool for promoting innovation in broad curricular design.

\section{METHOD AND FINDINGS}

For the development of this study, a systematic review (Gough, Oliver, \& Thomas, 2012; Boland, Cherry and Dickson, 2014) was carried out with the purpose of locating, appraising and synthesizing the best available evidence on the literature (Gough, Oliver, \& Thomas, 2012) concerning the relationship between the flipped classroom and its potential for transforming the curriculum. Systematic reviews are designed according to well-defined and transparent procedures with the aim of finding the maximum relevant research that is of interest for a particular investigation (Monteiro et al., 2016). As Pickering and Byrne (2014) suggest, this kind of approach is systematic as much as the methods used to survey the literature, and then select papers to include, are reproducible. Assuming that the method should not only be explicit but systematic 
with the ultimate goal of providing varied and reliable results (Monteiro et al., 2016), one can also acknowledge its comprehensive character since it addresses assessment on different combinations of locations, subjects and variables, which responses have been consistently examined by researchers and what they have found (Pickering and Byrne, 2014). In general, systematic reviews require the definition of a (i) review question or problem; (ii) the identification and critical assessment of the available evidence; (iii) a summary of the findings; and (iv) the drawing of pertinent conclusions (Boland, Cherry, \& Dickson, 2014; Monteiro et al., 2016). Among the advantages of a review of such character is the production of a map resembling a bigger picture of the object in focus (Tondeur et al., 2017). In the following sections, we detail the procedures followed and present description and analysis of the articles included in the review.

\section{Search Strategies and Review Question Design}

Ultimately, the goal of a systematic review permeates efforts to review and synthetize existing research to address a research problem or question (Monteiro et al., 2016). In this sense, once an issue is established, as well as the theoretical foundations, a protocol should be written (Gough, Oliver, \& Thomas, 2012). In general, the protocol covers descriptions on how studies are reached; what judgement relevant studies undergo regarding their usefulness in addressing the research problem; and how the results are aligned collectively to provide a measure of effectiveness (Monteiro et al., 2016). In our work, we relied on Boland, Cherry, and Dickson's (2014) approach, which consists of a nine-step systematic review process - where necessary, some adaptations took place. These steps range from performing scoping searches and identifying the review question to the writing up and editing of analysis and synthesis of data extraction. In terms of the protocol, we established the review question, a literature review strategy and inclusion, exclusion and quality assessment criteria of the articles. Also, we carried out procedures of data extraction and synthesis of results, deriving from a categorization model mainly developed at the data extraction stage, although not exclusively reminiscent of this step.

The general concern of this research regards the relationship of the flipped classroom model (e.g. Ayçiçek \& Yelken, 2018; Moran, 2018; Villalba, Castilla \& RedondoDuarte, 2018; Hendry et al., 2017; Kostaris et al., 2017; Kong, 2014) with processes of curriculum design. More specifically, we are interested in understanding the existing potential (if there is) of such pedagogical approach in promoting changes in the curricular culture of schools. Acknowledging education undergoes huge pressures of updating its culture to the new mandates of the $21^{\text {st }}$ century (Vincent-Lancrin, Jacotin, Urgel, Kar \& González-Sancho, 2017), which of course includes skills associated to the digital Era (Durak, 2018; Kong, 2014; Thomas \& Brown, 2011; Hannon, 2009), our hypothesis is that the flipped classroom model, which is becoming more and more popular, especially in higher education, can resource a reorientation of the work conducted in the school system. Because the project under which the research is carried out is aimed at teachers from primary and secondary school levels, we opted for favouring the literature review concerning such levels of education. Initial search scopes, though, clearly reveal that flipped classroom is much more spread in the higher education sector. Recognizing through these initial searches that fewer studies are 
available, we opted out for relying our systematic review under a research problem rather than a specific review question. For that reason, our approach considered all articles that would address the broad connection of flipped classroom/ flipped learning and school curriculum. After attempts to collect material, it is noteworthy that we gave up on the keyword "innovation" since results were frustratingly incipient. We, then, considered this character of innovation as part of data extraction and analysis, as discussed further.

\section{Inclusion and Exclusion Criteria}

Regarding the inclusion and exclusion criteria (Boland, Cherry and Dickson, 2014), identified articles were subject to a few principles. They should have been published in English, later than 2010, full texts must have been made available, and, more importantly, research needed to relate, at some extent, flipped classroom to issues of curriculum. No work focused on higher education was included, but vocational education at secondary school level was also considered. The review excluded materials concerning books, book chapters, procedures, opinion letters or similar. It was mandatory that selected articles had been submitted to peer review procedures. All studies that make up the synthesis of this work were located through solid search on Web of Science and ERIC databases. The words used in the literature search included flipped classroom together with curriculum and their respective synonyms. The school levels of our interest were associated to the search as well. Figure 1 provides an overview on the search arrangements.

[1] flipped cl assroom OR flipped learning OR flipped class

[2] curricul um QR program

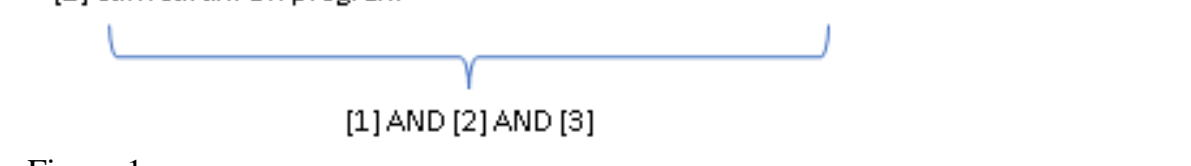

Figure 1

Word Search on Databases

After initial searching was performed, the articles were submitted to the defined criteria of inclusion and exclusion. A further step consisted of crosschecking the articles since we have performed searches in two different databases. Such stage guaranteed elimination of duplicates. In the meantime, there were also procedures of screening and quality assessment of materials. Figure 2 depicts the detailed arrangements of steps executed in the systematic review process. 


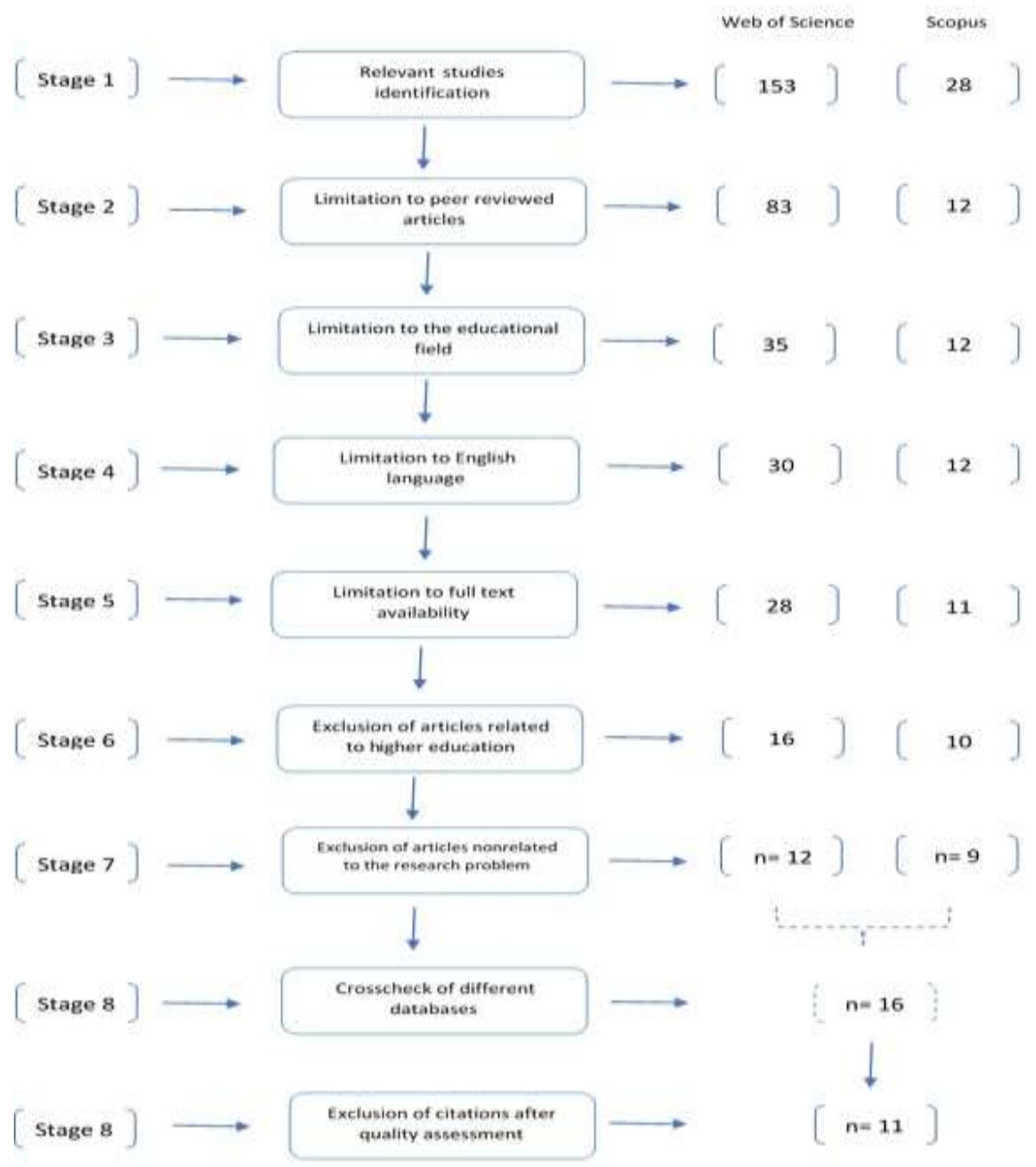

Figure 2

The Detailed Arrangements of Steps Executed in the Systematic Review Process

\section{Screening and Quality Assessment}

The remaining articles after stage five of the systematic review (Boland, Cherry, \& Dickson, 2014) were submitted to a screening process in which we read all titles, abstracts and keywords in order to infer if the studies were truly related to the scope of the research problem - the relationship between flipped classroom and curriculum design. Mainly, articles were excluded because they were associated to higher education, which is beyond our reach of interest. A few articles were also left behind 
due to not explicitly working either on the flipped classroom theme or the curriculum approach, despite highlighting these topics in titles or keywords. This decision can possibly be related to the fact that flipped classroom has become quite trendy in recent years (Durak, 2018; Lai \& Hwang, 2016; Cargile \& Sheats, 2015). Another relevant issue to mention on full-text final selection is that we narrowed language to English only. Nevertheless, it is noteworthy that Scopus database had no material on the research subject in other languages.

For the quality assessment stage, material had been pre-prepared while on stage six, since all papers at that moment had been imported to Nvivo12 Pro software. Throughout the screening of titles, abstracts and keywords, a descriptive summary of data was categorized already with the support of the software. As non-interesting articles were eliminated, the remaining sixteen papers were ready for further exploitation. A comprehensive reading of each paper was then performed leading to a final selection of eleven articles. For the quality assessment stage, we adapted the Critical Appraisal Skills Programme (CASP) Qualitative Checklist (2018). A sheet on Excel with all parameters listed on CASP (2018) was generated, including a column for each article and the material examined.

\section{Data Extraction}

Having finished the quality assessment stage, the remaining citations were organized according to data extraction procedures (Boland, Cherry \& Dickson, 2014). As stated before, while on stage six, all articles were uploaded to NVivo 12 Pro software and categorization on descriptive data had been coded since then. This data contained basic information such as methodology, institutional origin of authors and focus of each study. A second chain of nodes in NVivo were elaborated through extensive reading of material, originating the analytical data to be presented in the forthcoming sections. These data allow us to infer the kind of links established on literature about the relationship between flipped classroom and curriculum design at the same time they provide a view on routes explored and paths that are still open.

\section{Descriptive Data}

One appealing figure of this systematic review is the amount of work developed in Asian countries. Scholars from China, Hong Kong and Twain seem very enthusiastic on the methodological approach of the flipped model. Consistently, most of these studies support their research on empirical data, with a great deal of experimental trainings on the subject. They also recognize how widely the method has been applied to higher education, indicating the gap on information in what regards primary or secondary school levels, a fact that would corroborate the importance of their experiments. Recognizing the American origins of the flipped classroom method, Liu \& Feng (2015), for instance, make it central to their study, the cultural challenges posed by flipped approach at teachers, culturally speaking. Table 1 organizes the descriptive data of the analysed articles, providing essential information on their characterization and explicating their objects of interest. 
Table 1

Descriptive Data

\begin{tabular}{|c|c|c|c|}
\hline $\begin{array}{l}\text { Short } \\
\text { citation }\end{array}$ & Purpose & Methodology & Origin (institutional) \\
\hline Kong, 2014 & $\begin{array}{l}\text { Understand the potential of digital classrooms in } \\
\text { developing information literacy competency and } \\
\text { critical thinking skills through domain } \\
\text { knowledge learning }\end{array}$ & $\begin{array}{l}\text { Mixed method with } \\
\text { focus on quantitative } \\
\text { data }\end{array}$ & Hong Kong \\
\hline Kong, 2015 & $\begin{array}{l}\text { Assessment of critical thinking achievement } \\
\text { through pedagogical and technological support }\end{array}$ & $\begin{array}{l}\text { Longitudinal study of } \\
\text { mainly quantitative } \\
\text { nature }\end{array}$ & Hong Kong \\
\hline $\begin{array}{l}\text { Cargile \& } \\
\text { Sheats, } 2015\end{array}$ & $\begin{array}{l}\text { Examine how Khan Academy (KA) was used as } \\
\text { a tool for instruction in middle and high school } \\
\text { mathematics classrooms }\end{array}$ & $\begin{array}{l}\text { Qualitative study based } \\
\text { on students' voices and } \\
\text { experiences }\end{array}$ & USA \\
\hline $\begin{array}{l}\text { Liu \& Feng, } \\
2015\end{array}$ & $\begin{array}{l}\text { Examine dilemmas that teachers encounter } \\
\text { during educational borrowing in the global era }\end{array}$ & Qualitative study & China \\
\hline $\begin{array}{l}\text { Lai \& } \\
\text { Hwang, } \\
2016 \\
\end{array}$ & $\begin{array}{l}\text { Evaluate the effectiveness of a self-regulated } \\
\text { flipped classroom approach }\end{array}$ & $\begin{array}{l}\text { A quasi-experimental } \\
\text { approach of quantitative } \\
\text { nature }\end{array}$ & Taiwan \\
\hline $\begin{array}{l}\text { Kostaris et } \\
\text { al., } 2017\end{array}$ & $\begin{array}{l}\text { Studying the effect of the Flipped Classroom } \\
\text { approach in K-12 ICT teaching and learning }\end{array}$ & $\begin{array}{l}\text { Action research study } \\
\text { based on mixed } \\
\text { methods with focus on } \\
\text { quantitative approach }\end{array}$ & $\begin{array}{l}\text { Greece / Australia / } \\
\text { Norway }\end{array}$ \\
\hline $\begin{array}{l}\text { Hendry et } \\
\text { al., } 2017\end{array}$ & $\begin{array}{l}\text { Provide an overview of the introduction, } \\
\text { implementation, evolution, hybridization, and } \\
\text { initial research into the constructivist } \\
\text { instructional models deployed within a } \\
\text { secondary (high) school in Australia. }\end{array}$ & Quantitative nature & Australia \\
\hline $\begin{array}{l}\text { Ayçiçek \& } \\
\text { Yelken, } \\
2018\end{array}$ & $\begin{array}{l}\text { Determine the effect of flipped classroom model } \\
\text { on students' classroom engagement in teaching } \\
\text { English }\end{array}$ & $\begin{array}{l}\text { Quasi-experimental } \\
\text { pretest/posttest design } \\
\text { of mainly quantitative } \\
\text { nature }\end{array}$ & Tukey \\
\hline Durak, 2018 & $\begin{array}{l}\text { Investigate the effect of students' flipped } \\
\text { learning readiness (FLR) on engagement, } \\
\text { programming self-efficacy, attitude towards } \\
\text { programming, and interaction intensity in the } \\
\text { information and technology classrooms where } \\
\text { programming is taught with the flipped } \\
\text { classroom (FC) model }\end{array}$ & Quantitative study & Quantitative study \\
\hline $\begin{array}{l}\text { Villalba, } \\
\text { Castilla \& } \\
\text { Redondo- } \\
\text { Duarte, } 2018 \\
\end{array}$ & $\begin{array}{l}\text { Explore which factors impact on the adoption of } \\
\text { the flipped classroom in vocational education to } \\
\text { pave the way for the schools which want to } \\
\text { apply this model. }\end{array}$ & $\begin{array}{l}\text { Mixed method with } \\
\text { clear domain of } \\
\text { quantitative approach }\end{array}$ & Spain \\
\hline Moran, 2018 & $\begin{array}{l}\text { Assess student engagement during the flipped } \\
\text { model of instruction in two seventh-grade } \\
\text { English language arts (ELA) classrooms }\end{array}$ & Mixed method & USA \\
\hline
\end{tabular}

\section{Analytical Data}

Once gathered basic and descriptive information of the articles included in this systematic review, we developed further analysis on the data presented. The categorization spread to findings and relations established between the flipped classroom model and curriculum, in order to identify main topics and nature of interpretation that researchers have reached. Extensive reading of papers and their results led to the proposition of three subcategories, labelled as (i) outcomes support, (ii) institutional change, and (iii) classroom instruction modus operandi. For each of them, 
the analytical framework advanced in specific purposes/goals related to the deployment of the flipped classroom model in educational context, considering the strings to curriculum design/orientation as well.

It is appealing that most studies derive from the implementation of flipped learning modules with the broad purpose of assessing its potentiality to enhance students' outcomes. Only two articles are focused specifically on the point of view of teachers regarding the method, while there is a third one which results draw especially on students' experience, but also provides insights of teachers' perceptions on the adoption of flipped classes. Among all articles, there is a single one in which empirical data rely on flipped classroom perceptions that are not related to an intervention administered or somehow closely followed by the researchers themselves. In this specific case, the author seeks for evidence on a tool widely applied on math classes in the USA. Figure 3 presents a synthesis of the analytical data's categorization.

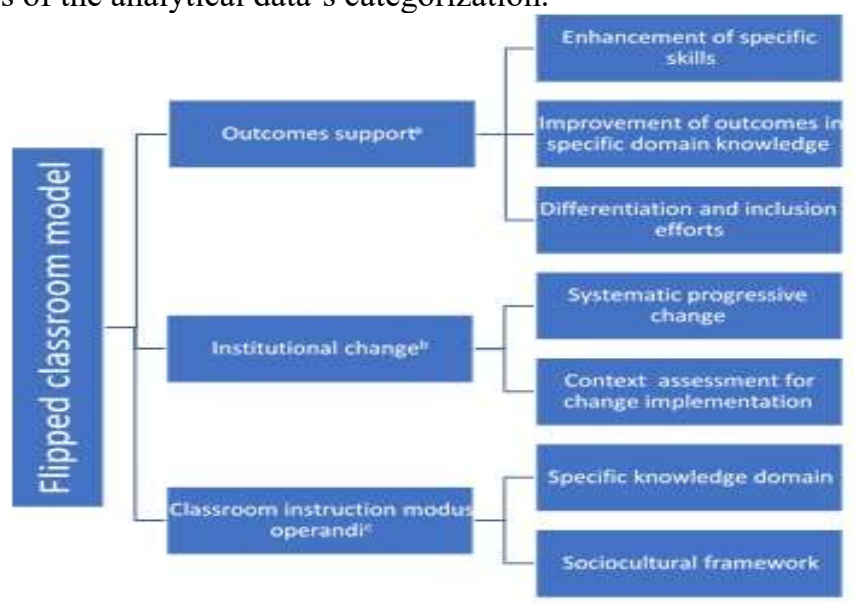

Short Citation

Kong, 2014; Kong, 2015; Lai \& Hwang, 2016 ; Kostaris et, al., 2017 ; Cargile \& Sheats, 2015

${ }^{b}$ Hendry et. al, 2017: Villalba, Castilla \& Redondo-Duarte, 2018

- Liu \& Feng, 2015; Ayçiçek \& Yelken, 2018; Durak. 2018: Moran, 2018

Figure 3

Analytical Data Categories

\section{DISCUSSION}

Our departure standpoint concerning the flipped classroom/flipped learning model concerns the links literature permeates of its deployment with curricular work. For that, we have searched databases for papers establishing ties within these themes. According to our analysis, the resource on flipped classes in basic (primary or elementary) and 
secondary schools is still innovative. There's consistent research on how post-secondary education applies the method and perceptions of how it can benefit the learning process (Kostaris et al., 2017), nonetheless, the flipped model seems to continue in an exploring/experimental moment when it comes to primary and secondary education. The research addressed in this article regards a considerable number of interventions in the school setting, especially of short-term duration, within specific domain learning.

An overview of the findings and approaches imprinted in works that explore the flipped classroom model led us to build a framework that underpins three research perspectives: resource on the flipped learning to promote (i) outcomes support; deployment of the method in a more systematic way to endorse (ii) institutional change; and reflection on the potentialities of the method as (iii) classroom instruction modus operandi.

The majority of works falls in the first category, concerning the feed of better practices to promote students' achievement. Within this category, we have identified other three domains that enlighten the strategy or motifs why the flipped classroom model is addressed. The first of these subcategories entails the empowerment of the flipped approach through association with other learning strategies. This is the main theme in the work of Lai \& Hwang (2016) who defend that flipped learning can be improved by appraising self-regulated strategies in the educational process. According to these authors, besides engendering a more active way of learning through the flipped model, it is also possible to enhance students' self-efficacy when the method explicitly approaches a self-regulated strategy. This subcategory also encompasses the enrichment of specific skills, such as information literacy or critical thinking (Kong, 2014; 2015) while a second one considers the addressing to specific knowledge domain, like ICT teaching (Kostaris et al., 2017), as a focus of change; finally, there is explicit interest on how the flipped method can allow a more inclusive learning environment, fostering processes of pedagogical differentiation (Cargile \& Sheats, 2015) as organized in the third subcategory.

Another category in which we organized the relationship between the flipped learning and curriculum is the (ii) institutional change. It is key to the discussion of the method since it reflects upon a more structured and holistic approach concerning the adoption of flipped learning. In here, two works of very different nature fit. One of them consists of an integrated analysis of different action taken in an Australian school that privileges constructivist instructional models in lower and upper secondary levels of education. Focused on students' outcomes and comprising a set of diverse quantitative data, the work of Hendry et al. (2017) highlights that students highly appreciate the flipped classroom approach. Based on a literature review, these authors developed an instrument to evaluate students' perceptions of the flipped classroom consisting of nine domains: homework, technology and collaboration, use of class time, teacher role, engagement, self-efficacy, interest, self-directedness and learning extent. The authors sustain that initial data on students' standardized examinations corroborate the idea that constructivist approaches, to which the flipped classroom links, present no constraints to academic achievements. 
The significant outcomes and excitement of students addressed by Hendry et al. (2017) regarding the deployment of constructivists methods assembly a set of structural and procedural changes within the school culture. The authors affirm that to effect meaningful change it must occur on a large scale, assuming that approaches are constrained by the physical, environmental and educational structures. According to Hendry et al. (ibid.), the improvement of educational outcomes for students are the immediate result of a combination comprising elements such as teacher training, collective efficacy and changes to the learning environment.

With a similar perspective in what concerns the view of change as a systematic initiative, Villalba, Castilla \& Redondo-Duarte (2018) organize the perceptions, attitudes and experiences of teachers on the implementation of the flipped method. Their study collect data from teachers working in three different countries and reassure a known thread in innovation - it usually portrays individual character rather than a strong collective organized action. Aiming at developing parameters to support curriculum change in vocational schools, Villalba, Castilla \& Redondo-Duarte (ibid.) highlight that factors such as teacher training, level of resources, pedagogies and teaching practices, attitudes of teachers, ICT competence and positive attitude towards innovation influence the use of technology in teaching methodologies.

Both works categorized as (ii) institutional change about the links assembled between the flipped method and curriculum portray a robust message that incorporating innovation only becomes sustainable when there are traces of collective endorsement and a basic set of resources. While Hendry et al. (2017) pinpoint gradual steps in the pursuit of educational change as a meaningful action, reinforcing the importance of professional development, Villalba, Castilla \& Redondo-Duarte (2018) call attention to the fact that basic infrastructure is necessary to promote change. These authors also relate that in the specific case of flipped learning, teacher training might mean very different needs from context to context, in terms of what guidance is necessary to take action. Together, these works build on «how» systematic change can take place. Differently of other citations discussed in here that implemented experimental approaches and then reflected upon them, the articles oriented for (ii) institutional change, despite also taking experiential action, tend to keep an eye in the future, strategically identifying factors that might ease forthcoming work on innovative methodologies like the flipped model.

Finally, the third category, (iii) classroom instruction modus operandi, gathers research which addresses the flipped approach in exploratory ways, testing or assessing its potentialities and disadvantages as instructional policy. A commonality of this sort of study is that all of them rely on the implementation of programs based on the flipped classroom model. Not taking for granted their goal to cover achievements improvement, as it happens in the (i) outcomes support category, these articles favour a more holistic view on the flipped learning, rationalizing its variables in the sense of instruction. Primarily, the authors connect the flipped learning to specific knowledge domains, be it English (Ayçiçek \& Yelken, 2015), Information Technology and Software (Durak, 2018) or English Language Arts (Moran, 2018). Inside this category, we find a relevant 
discussion on how cultural aspects moulds education perspectives and interferes in the adherence to possible innovative learning scenarios.

Despite the focus on China, Liu \& Feng (2015) assessment of borrowing policies enlighten some barriers that the flipped learning can face in the western world too. Their work reinforces that understanding of knowledge production, transmission and purpose are traits that interfere directly on the disposition of teachers to apply a certain mode of instruction. Consequently, it raises a debate on the possible disconnection between a more active way of teaching that presupposes the development of soft skills meanwhile and the pressure for achievement in standard examinations. As we have identified, there is evidence that contradicts the notion that innovation and the implementation of constructivist approaches to learning can constitute a barrier to standardized exit exams (Hendry et al., 2017). It doesn't diminish the role of teachers' beliefs in the adoption of a certain learning approach though, an aspect that needs to be considered when curricular or institutional change is desired.

Among these papers that reflect on the flipped classroom as instructional approach, there is defence on the method capability to foster students' interaction and engagement with subject domain (Ayçiçek \& Yelken, 2018); argumentation on the importance of teachers' guidance to secure students successful handling of online and face to face tasks (Durak, 2018); and acknowledgment that students may have mixed feelings concerning the flipped approach (Moran, 2018). Grounding her findings on the idea that for some students, independently of the instructional method, school is school, Moran (2018) adverts that a few students might fall to boredom within this approach, either due to their perception of what school means or their negative disposition regarding the acceptance of new academic ideas. Based on her results, the author suggests that the flipped classroom should be addressed as a potential tool for specific domain teaching rather than the only one. Her work contradicts most of the studies cited in here, which results point out to students' excitement in using a flipped method.

The trends observed and organized in the literature that associates the flipped classroom/flipped learning with curriculum can be summarized into three routes then: the «what», in which articles focus on possibilities and potentialities that the flipped model can feed in terms of educational activities. They might split into subject domains or specific skills acquisition - see category (i) outcomes support; the «means», in which further data is gathered with the clear goal of understanding deep consequences of the flipped method deployment in instructional terms - see category (iii) classroom instruction modus operandi; and the «how», in which assessment of ongoing practices help understand how educational change can be performed through resourcing on the flipped methodologies, when a clear institutional holistic change goal is on the spotlight - see category (ii) institutional change.

\section{CONCLUSIONS}

The systematic review we reported in this article began from a research problem that we wanted to deepen: the flipped classroom model as a possible promoter of innovation in curriculum design. We conjecture that the flipped classroom model can resource a 
reorientation of the work conducted in the school system. To frame our research, we have tried to establish the relationship between the flipped classroom model and curriculum design.

Our systematic review identified 181 relevant studies in the Web of Science and Scopus databases. After a first critical review that included the previously defined inclusion and exclusion criteria, sixteen articles were selected for examination. In a subsequent step of evaluating the quality of the material obtained, eleven studies remained for further analysis.

The studies were grouped into three categories: (i) outcomes support, (ii) institutional change, and (iii) classroom instruction modus operandi.

The first category - (i) outcomes support - relates to the use of the flipped model for better classroom practices and student performance. It has been divided into three subcategories that clarify the strategy or reasons why the flipped classroom model is addressed. The first subcategory - Enhancement of specific skills - entails the empowerment of the flipped approach through association with other learning strategies as a way of generating a more active learning and as a means of placing the student in the process of regulating their own learning. It also covers development of skills in varied targeted areas, such as information literacy or critical thinking. The second subcategory - Improvement of outcomes in specific domain knowledge - is also centred on boosting students' results, but in this case, they are focused on certain content-areas, like ICT teaching. The third subcategory - Differentiation and inclusion efforts - is driven by explicit interest in revealing the potential of flipped learning into promoting a more inclusive learning environment, allowing the exploitation of pedagogical differentiation.

The second category - (ii) institutional change - supports the flipped classroom as a constructivist instructional model that is agreeable to students. It is key to the apprehension of the flipped model since it purposes rationalizing on a more structured and holistic implementation of the approach. The first subcategory - Systematic progressive change - explores ways of driving school culture towards a more active student-centred learning environment, considering its combination with other institutional features, including teaching training and collective efficacy. The second subcategory - Context assessment for change implementation - reveals efforts to apprehend mediation elements of sustainable change in educative environment. In this sense, studies are oriented to perceive constraints and facilitators in the implementation of innovative experiences within school learning approaches. Studies organized in this domain are future oriented, based on large scale change aims.

The third category - (iii) classroom instruction - addresses the flipped approach assessing its potentials and limitations concerning teaching issues. Authors reflect on the flipped classroom as instructional approach; there is a defence on the method capability to foster students' interaction and engagement with subject domain; and argumentation on the importance of teachers' guidance instead of lecturing, thus changing the role of the teacher in the classroom. Anyway, it is suggested that the flipped classroom should 
be addressed as a model with potential but not the only one. Although most of the authors cited point to the excitement of students to use a flipped approach, there is evidence showing some learners have mixed feelings about its experience. In the first subcategory - Specific knowledge domain - we realize a myriad of studies focused on experimental use of the flipped model to address content-area teaching. The second subcategory - Sociocultural framework - enlightens a relevant discussion on how cultural aspects shape education perspectives and interfere with adherence to possible innovative learning scenarios. The argument is that educating and the purpose of gaining knowledge is not universally understood. As such, these conceptions interfere directly with the teachers' willingness to apply a particular mode of instruction. One can question the meaning of active methods when the development of social skills is not at stake on educational goals panel, for example. Also, why would a teacher implement constructivist approaches to learning if inferring these approaches as a barrier to standardized exams?

When crossing the different categories of the model we reached through assessing literature, it is unveiled the potential of the flipped model to flip the curriculum and even the school culture. It cannot be taken as a sole strategy for the promotion of innovation in schools, although the registered ongoing experiences suggest resourcing education on the flipped approach can foster students' outcomes. Clearly, the model can ease the articulation and consolidation of constructivist approaches that are effective in the addressing of standardized educational assessment instruments as well. For that, it is a fertile tool to be continually integrated into the teaching and learning processes, when there is an evident pursuit of engaging students actively in their knowledge building.

This article's systematic review establishes that little research has been carried out in the context of non-tertiary education concerning the flipped method. In Portugal, for example, very limited experiences are registered (none appear in the indexed databases we relied on), reinforcing Rekindle +50 project innovative character and interest. Fostering teachers' digital migration in a world driven by technology is a singular step towards enhancing the quality and updating of educational systems. Admitting that teaching force in Europe, and beyond, is undergoing intense ageing processes also emphasizes the need of actions determined to flip school's nature to one more linked to the broad society's mandate. To meet this goal, the flipped method emerges as a promising tool to support bridging the gap between school culture and the $21^{\text {st }}$ century society nature. Meaningful change, as data points out, depends on large scale action, so the collaboration of diverse stakeholders must be based on systematic transformation in schools. Only in that sense, innovation through flipped learning can be successfully achieved. As we see, the Digital Era, after all, cannot be successfully accomplished without school's prominent role within this framework.

\section{LIMITATIONS OF OUR SYSTEMATIC REVIEW}

A limitation of any systematic review is the bias in selecting articles and in data extraction due to our choices of inclusion and exclusion criteria, and the databases we decided to use. Aware of this, we have tried to be rigorous in developing a proper protocol that represents the search problem, identifies keywords, and provides search 
strings to identify relevant literature. However, due to our choices, there is a risk that related studies have been excluded from our systematic review.

\section{ACKNOWLEDGMENT}

This article was developed within the project Digital migrations and curricular innovation: giving new meaning to experience and rekindling teaching profession after 50, funded by the Portuguese Foundation for Science and Technology (FCT), under the grant PTDC/CED-EDG/28017/2017.

\section{REFERENCES}

Ayçiçek, B., \& Y. Yelken, T. (2018). The effect of flipped classroom model on students' classroom engagement in teaching English. International Journal of Instruction, 11(2), 385-398.

Baruch, A. F., \& Erstad, O. (2018). Upbringing in a digital world: Opportunities and possibilities. Technology, Knowledge and Learning, 23, 377-390. doi: 10.1007/s10758018-9386-8.

Bingimlas, K. A. (2009). Barriers to the successful integration of ICT in teaching and learning environments: A review of the literature. Eurasia Journal of Mathematics, Science and Technology Education, 5(3), 235-245. doi:10.12973/ejmste/75275.

Boland, A., Cherry, G., \& Dickson, R. (2014). Doing a systematic review: A student's guide. London: SAGE Publications LTD.

Cargile, L. A., \& Sheats, S. (2015). Flip or flop? Are math teachers using khan academy as envisioned by Sal Khan? TechTrends, 59(6), 21-27.

Carrilo, C., \& Flores, M. A. (2018). Veteran teachers' identity: What does the research literature tell us? Cambridge Journal of Education, 48(5), 639-656. doi: 10.1080/0305764X.2017.1394982.

Chandra, V., \& Mills, K. A. (2015). Transforming the core business of teaching and learning in classrooms through ICT. Technology, Pedagogy and Education, 24(3), 285301.

Durak, H. Y. (2018). Flipped learning readiness in teaching programming in middle schools: Modelling its relation to various variables. J Comp Assist Learn., 34, 939-959.

Earle, R. S. (2002). The integration of instructional technology into public education: Promises and challenges. ET Magazine, 42(1), 5-13.

Gough, D., Oliver, S., \& Thomas, J. (2012). An introduction to systematic reviews. London: SAGE Publications.

Greany, T., \& Waterhouse, J. (2016). Rebels against the system. Leadership agency and curriculum innovation in the context of school autonomy and accountability in England. International Journal of Educational Management, 30(7), 1188-1206. doi: 10.1108/IJEM-11-2015-0148. 
Hanon, V. (2009). 'Only connect!': A new paradigm for learning innovation in the 21st century. Victoria: Centre for Strategic Education.

Hendry, A., Hays, G., Challinor, \& Lynch, D. (2017). Undertaking educational research following the introduction, implementation, evolution, and hybridization of constructivist instructional models in an Australian PBL high school. Interdisciplinary Journal of Problem-Based Learning, 11(2). doi: 10.7771/1541-5015.1688.

Kong, S. C. (2014). Developing information literacy and critical thinking skills through domain knowledge learning in digital classrooms: An experience of practicing flipped classroom strategy. Computers \& Education, 78, 160-173.

Kong, S. C. (2015). An experience of a three-year study on the development of critical thinking skills in flipped secondary classrooms with pedagogical and technological support. Computers \& Education, 89, 16-31

Kostaris, C., Sergis, S., Sampson, D. G., Giannakos, M. N., \& Pelliccione, L. (2017). Investigating the potential of the flipped classroom model in K-12 ICT teaching and learning: An action research study. Educational Technology \& Society, 20(1), 261-273.

Lafarrière, T., Law, N., \& Montané, M. (2012). An international knowledge building network for sustainable curriculum and pedagogical innovation. International Education Studies, 5(3), 148-160.

Lai, C., \& Hwang, G. (2016). A self-regulated flipped classroom approach to improving students' learning performance in a mathematics course. Computers \& Education, 100, 126-140.

Lakkala, M., \& Ilomaki, L. (2015). A case study of developing ICT-supported pedagogy through a collegial practice transfer process. Computers \& Education, 90, 1-12. doi: 10.1016/j.compedu.2015.09.001.

Leahy, S. M., Holland, C., \& Ward, F. (2019). The digital frontier: Envisioning future technologies impact on the classroom. Futures, 113, 2-10. doi: 10.1016/j.futures.2019.04.009.

Liu, S., Feng, D. (2015). How culture matters in educational borrowing? Chinese teachers' dilemmas in a global era. Cogent Education, 2, 1-15.

Louws, Monika L., Meirink, Jacobiene A., Veen, Klaas van, \& Driel, Jan H. van (2017). Teachers' self-directed learning and teaching experience: What, how and why teachers want to learn. Teaching and Teacher Education, 66, 171-183.

Monteiro, S., Lencastre, J. A., \& Osório, A. J. (2016). Course design in e-learning and the relationship with attrition and dropout: A systematic review, In $4^{\text {th }}$ International Instructional Technologies \& Teacher Education Symposium. Re-discover learning with digital learners. Book of proceedings (pp. 584-589). Elazig: Firat University. 
Moran, C. M. (2018) “Just don't bore us to death": Seventh graders' perceptions of flipping a technology-mediated English language arts unit. Middle Grades Review, 4(1), Article 5.

Morgado, J. C. (2017). Desafios curriculares para uma escola com futuro, ELO, 24, 3744

OECD (2010). Inspired by technology, driven by pedagogy. A systematic approach to technology-based school innovations. Educational Research and Innovation Series. [S.1.]: OECD.

OECD (2018). Education at a glance 2018: OECD Indicators. Paris: OECD Publishing.

Orlando, J. (2014). Veteran teachers and technology: change fatigue and knowledge insecurity influence practice. Teachers and Teaching, 20(4), 427-439. doi: 10.1080/13540602.2014.881644.

Pickering, C., \& Byrne, J. (2014). The benefits of publishing systematic quantitative literature reviews for $\mathrm{PhD}$ candidates and other early-career researchers. Higher Education Research \& Development, 33(3), 534-548.

Snoeyink, R., \& Ertmer, P. A. (2001). Thrust into technology: How veteran teachers respond. Journal of Educational Technology Systems, 30(1), 85-111.

Tondeur, J., Braak, J., Ertmer, P. A., \& Ottenbreit-Leftwich (2017). Understanding the relationship between teachers' pedagogical beliefs and technology use in education: A systematic review of qualitative evidence. Education Tech Research Dev, 65, 555-575.

Thomas, D., \& Brown, J. S. (2011). A new culture of learning. Cultivating the imagination for a world of constant change. [S. 1.]: CreateSpace.

Villalba, M. T., Castilla, G., \& Redondo-Duarte, S. (2018). Factors with influence on the adoption of the flipped classroom model in technical and vocational education. Journal of Information Technology Education: Research, 17, 441-469.

Vincent-Lancrin, S., Jacotin, G., Urgel, J., Kar, S., \& González-Sancho, C. (2017). Measuring innovation in education: A journey to the future. Paris: OECD Publications.

Willness, C., \& Bruni-Bossio, V. (2017). The curriculum innovation canvas: A design thinking framework for the engaged educational entrepreneur. Journal of Higher Education Outreach and Engagement, 21(1), 134-164. 